\title{
Case Report: Approach to Tinea incognito
}

\author{
Mehmet Ziya Gençer* \\ Turkish Institution of Public Health, Family Health Center, Turkey \\ *Corresponding author: Mehmet Ziya Gençer, Turkish Institution of Public Health, Cankaya No: 2 Family Health Center, Ankara, Turkey
}

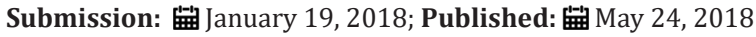

\section{Introduction}

Tinea incognito is a disease that gets the look of atipic form of mycotic infection, imitating many different dermatomes formed by misdiagnosing and giving improper topical, systemic steroids or immune suppressive therapy. Tinea incognito or steroid modified tinea is a dermatophytic infection in which topical or systemic steroids, administered as a result of dermatological misdiagnosis or pre existing pathologies, have modified the clinical appearance of the fungal infection, transforming the typical ring worm and mimicking other skin diseases [1,2].

In this case we demonstrate a patient who started topical corticosteroids application with misdiagnosis and after that insisting topical corticosteroids use on her treatment from doctors she see.

\section{Case}

Forty-two-year-old female consulted to our clinic with severe itch, rash, redness that started at inguinal region and spreaded to belly region. Patients complaints is ongoing for 5months and she first admitted to the pharmacy and given herklobetazolpropiyonat cream for itching. Later while she was out of town prescribed same medicine to a family doctor. Patient stated that given cream reduced itching and after stop using medicine itches increased and worsened. Patient related rise of complaints with "unfinishing "treatment. Patient has requested the re-prescription of the same medicine from our clinic "to be able to continue treatment". The patient has been informed and convinced to an examination. During examination erythematous papules and squamous plaques with unclear boundaries seen examination in the belly and around the inguinal region. From the anamnesis taken from the patient and clinical look disease thought as tinea incognita. Terbinafine $250 \mathrm{mg}$ /day, isoconazole cream (2times a day) and terbinafine spray (2times a day) started on her. In her supervision a week later lesions and complaints were seen reduced and totally disappeared in four weeks.

\section{Conclusion}

Tinea incognito has been used to describe a dermatophyte infection modified by corticosteroid treatment. Lesions are often a typical appearing and the diagnosis can be delay edormissed [3]. The clinic of tinea incognito is quite typical. As a result of using cortices teroids, immune system suppressed and the beginning clinical signs depends on dermatophyte infection to become indistinct, rash disappeared but fungal infection gradually spread. Patients forced to use drugs repeatedly, and this becomes avicious cycle. This clinic properties caused by steroids should be kept in mind by the family doctors, also society should made aware of the drawbacks of using unprescripted drugs.

\section{References}

1. Romano C, Maritati E, Gianni C (2006) Tinea incognito in Italy: a 15-year survey. Mycoses 49(5): 383-387.

2. Elgart ML (1996) Tinea incognito. Dermatol clin 14(1): 51-55.

3. Kang HY, Son HC, Lim YS, Cho YW, Han JY (2000) A case of tinea incognito on the face due to Tricho phytonmentagrophytes. Korean Journal of Dermatology 38(8): 1124-1126.
Creative Commons Attribution 4.0 International License

For possible submissions Click Here

\section{Submit Article}

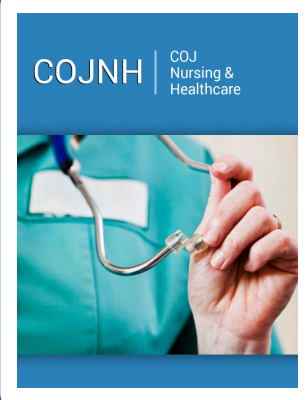

COJ Nursing \& Healthcare

Benefits of Publishing with us

- High-level peer review and editorial services

- Freely accessible online immediately upon publication

- Authors retain the copyright to their work

- Licensing it under a Creative Commons license

- Visibility through different online platforms 